\title{
Attention is complex: causes and effects
}

\author{
Olivier A. Coubard ${ }^{1,2 *}$ \\ 1 The Neuropsychological Laboratory, CNS-Fed, Paris, France, ${ }^{2}$ Laboratoire Psychologie de la Perception, UMR 8242 \\ CNRS-Université Paris Descartes, Paris, France
}

Keywords: attention, selection, basal ganglia, superior colliculus, theory

\section{A Commentary on}

\author{
Attention as an effect not a cause \\ by Krauzlis, R. J., Bollimunta, A., Arcizet, F., and Wang, L. (2014). Trends Cogn. Sci. 18, 457-464. \\ doi: 10.1016/j.tics.2014.05.008
}

Recently, Krauzlis et al. (2014) introduced a framework in which attention arises from value-based decision-making mechanisms centered on basal ganglia. Appropriate decision-making is made by identifying the current "state" of the animal and its environment. Defining a state requires interpreting different sources of information from the subject's internal and external world, knowledge and needs. The authors provide evidence from physiology, neuroanatomy, clinical studies and modeling. Here I re-examine this framework in the light of the following keys that help understand a cognitive function: its architecture and neural correlates, its process and mechanisms, its theory and metaphors. The component of attention described by Krauzlis et al. arises as a functional consequence of basal ganglia activity, suggesting that it may be treated as an effect not a cause (Krauzlis et al., 2014).

Since the original work by James (1890/1950), thousands of contributions have been published in the field of attention (e.g., over 59791 articles in PudMed with "attention" as a subheading). From this ocean of research, some consensus has emerged about the architecture of attention. In psychology, three attention macrosystems have been delineated: arousal or vigilance, selective attention or selection, and attentional control (Pashler, 1998). These modules have been validated by physiology as corresponding to distinct neural networks of the animal (Maunsell, 2004) and of the human (Parasuraman, 2000) brains. Vigilance has been associated with the activity of brainstem reticular formation and diffuse thalamic substance (Robbins, 1997; Coull, 1998; Paus, 2000); selection with that of cortical-particularly parietal—and subcortical areas (Snow et al., 2009; Lovejoy and Krauzlis, 2010; Capotosto et al., 2013); and control with that of cortical-particularly prefrontal—and subcortical areas (Desimone et al., 1990; Knight et al., 1995; Stuss, 2006). In light of this architecture, I suggest that Krauzlis et al. (2014)'s model might not concern attention as a whole but may be restricted to one attentional system: selection and even more spatial selection. My argument is twofold. First, 32 of their 102 references $\left(\mathrm{n}^{\circ} 1,2,3,4,5,6,7,8,11,12,13,14,15,16,24,33,44\right.$, $52,53,54,55,56,58,59,60,64,65,66,67,68,75,100)$ are dedicated to selection whereas 0 and $1\left(n^{\circ} 81\right)$ respectively concern vigilance and control. Second, the reported neural bases and related brain damages are compatible with those of selection and related disorders: spatial neglect and Parkinson's disease (Krauzlis et al., 2014).

With respect to the process, the macromechanism regulating attention uses subcortical pathways. First, Krauzlis et al. suggest that the route from superior colliculus (SC) to medial dorsal nucleus of thalamus provides corollary discharge signals about eye movements to frontal eye field and convey signals to the striatum through prefrontal cortex. Second, the route from SC intermediate layers to the parafascicular nucleus through thalamus 
would be the predominant source of thalamus inputs to pathways in the striatum. Third, the route from SC intermediate layers to substantia nigra pars compacta would provide signal related to the detection of salient sensory events. Other routes leading to basal ganglia may play a role in this non-cortical circuit for attention (Krauzlis et al., 2014). It is a quality of the authors to rehabilitate the subcortex in (selective) attention and to recall that attention is not the exclusivity of cortex. They indeed review that invertebrates (honeybees, Drosophilia) or vertebrates without cortices (pigeons, peacocks, owls, frogs, salamanders or zebrafish) do exhibit signs of attention. Such model is reminiscent with (pre)motor theories of attention highlighting the role of subcortical areas in attention-whether it be called attention, imagination, emulation, simulation or projection. Nineteen years ago, Berthoz (1996) suggested the role of areas from brainstem to basal ganglia in imagination as a functional consequence of movement gating, and Kustov and Robinson (1996) demonstrated the critical role of SC in attention shifts. At the cell level, the micromechanism by which basal ganglia inputs are differentially weighted uses a process similar to Bayesian inference (Krauzlis et al., 2014). In this way, the model partially resembles competition models, whether they be called diffusion (Ratcliff, 1978), linear approach to threshold with ergodic rate (Carpenter, 1981) or race (Schall, 1995).

With regard to the theory, given that alternatively "everyone" (James, 1890/1950) and "no one" (Pashler, 1998) knows what attention is, the history of psychology has exploited different metaphors to account for what attention can be. The debates have turned around early vs. late filtering (Treisman, 1969), excitatory vs. inhibitory mechanisms (Laberge and Brown, 1989),

\section{References}

Awh, E., Belopolsky, A. V., and Theeuwes, J. (2012). Top-down versus bottomup attentional control: a failed theoretical dichotomy. Trends Cogn. Sci. 16, 437-443. doi: 10.1016/j.tics.2012.06.010

Berthoz, A. (1996). The role of inhibition in the hierarchical gating of executed and imagined movements. Brain Res. Cogn. Brain Res. 3, 101-113. doi: 10.1016/0926-6410(95)00035-6

Capotosto, P., Tosoni, A., Spadone, S., Sestieri, C., Perrucci, M. G., Romani, G. L., et al. (2013). Anatomical segregation of visual selection mechanisms in human parietal cortex. J. Neurosci. 33, 6225-6229. doi: 10.1523/JNEUROSCI.498312.2013

Carpenter, R. H. S. (1981). “Oculomotor procrastination,” in Eye Movements: Cognition and Visual Perception, eds D. F. Fisher, R. A. Monty, and J. W. Senders (Hillsdale, NJ: Lawrence Erlbaum), 237-246.

Coull, J. T. (1998). Neural correlates of attention and arousal: insights from electrophysiology, functional neuroimaging and psychopharmacology. Prog. Neurobiol. 55, 343-361. doi: 10.1016/S0301-0082(98)00011-2

Desimone, R., and Duncan, J. (1995). Neural mechanisms of selective visual attention. Annu. Rev. Neurosci. 18, 193-222. doi: 10.1146/annur ev.ne.18.030195.001205

Desimone, R., Wessinger, M., Thomas, L., and Schneider, W. (1990). Attentional control of visual perception: cortical and subcortical mechanisms. Cold Spring Harb. Symp. Quant. Biol. 55, 963-971. doi: 10.1101/SQB.1990.055.01.090

Fernandez-Duque, D., and Johnson, M. L. (2002). Cause and effect theories of attention: the role of conceptual metaphors. Rev. Gen. Psychol. 6, 153-165. doi: 10.1037/1089-2680.6.2.153

James, W. (1890/1950). The Principles of Psychology. New York, NY: Dover.

Knight, R. T., Grabowecky, M. F., and Scabini, D. (1995). Role of human prefrontal cortex in attention control. Adv. Neurol. 66, 21-34. discussion: 34-26. or bottom-up (i.e., stimulus-driven or exogenous) vs. top-down (i.e., goal-directed or endogenous) processes (Awh et al., 2012). The cause vs. effect nature of attention has been reviewed by Fernandez-Duque and Johnson (2002), and the idea that attention may be an effect not a cause has been advanced by Desimone and Duncan (1995). In that sense, attention is an emergent property or epiphenomenon of the fact that when stimulus representations compete for processing resources, one of them wins (Fernandez-Duque and Johnson, 2002). In Krauzlis et al. (2014)'s model, attention is a functional consequence of the competition between basal ganglia circuits. Like other competition models, it has the advantage of banishing the control homunculus (Monsell and Driver, 2000) and the disadvantage of seeing attention as something we can do without (Fernandez-Duque and Johnson, 2002). But Krauzlis et al. (2014) also admit that control is still needed. Indeed they indicate that one function of inputs from prefrontal cortex to striatum could be to provide additional nonsensory inputs to expand the number of states and associated value functions that can be acquired. For that reason, I suggest that Krauzlis et al. (2014)'s model is likely to be a "biased competition model" according to Fernandez-Duque and Johnson (2002)'s taxonomy. Though the concept of a central executive is eliminated, the model is still using feedback loops that bias the information processing of upcoming stimuli. However the question of how such modulation gets decided remains a mystery. This leads me to the conclusion that Krauzlis et al. (2014)'s model does not prove attention to be mainly an effect. Rather their model may be a hybrid theory in which attention is complex, comprising causes and effects, where there is still room for attention as a cause.

Krauzlis, R. J., Bollimunta, A., Arcizet, F., and Wang, L. (2014). Attention as an effect not a cause. Trends Cogn. Sci. 18, 457-464. doi: 10.1016/j.tics.2014.05.008 Kustov, A. A., and Robinson, D. L. (1996). Shared neural control of attentional shifts and eye movements. Nature 384, 74-77. doi: 10.1038/384074a0

Laberge, D., and Brown, V. (1989). Theory of attentional operations in shape identification. Psychol. Rev. 96, 101-124. doi: 10.1037/0033-295X.96.1.101

Lovejoy, L. P., and Krauzlis, R. J. (2010). Inactivation of primate superior colliculus impairs covert selection of signals for perceptual judgments. Nat. Neurosci. 13, 261-266. doi: 10.1038/nn.2470

Maunsell, J. H. (2004). Neuronal representations of cognitive state: reward or attention? Trends Cogn. Sci. 8, 261-265. doi: 10.1016/j.tics.2004.04.003

Monsell, S., and Driver, J. (2000). "Banishing the control homonculus," in Control of Cognitive Processes. Attention and Performance XVIII, eds S. Monsell and J. Driver (Cambridge: The MIT Press), 3-32.

Parasuraman, R. (2000). The Attentive Brain. Cambridge, MA: MIT Press.

Pashler, H. E. (1998). The Psychology of Attention. Cambridge, MA: The MIT Press.

Paus, T. (2000). Functional anatomy of arousal and attention systems in the human brain. Prog. Brain Res. 126, 65-77. doi: 10.1016/S0079-6123(00)26007-X

Ratcliff, R. (1978). A theory of memory retrieval. Psychol. Rev. 85, 59-108. doi: 10.1037/0033-295X.85.2.59

Robbins, T. W. (1997). Arousal systems and attentional processes. Biol. Psychol. 45, 57-71. doi: 10.1016/S0301-0511(96)05222-2

Schall, J. D. (1995). Race to explain procrastination. Nature 377, 14-15. doi: $10.1038 / 377014 \mathrm{a} 0$

Snow, J. C., Allen, H. A., Rafal, R. D., and Humphreys, G. W. (2009). Impaired attentional selection following lesions to human pulvinar: evidence for homology between human and monkey. Proc. Natl. Acad. Sci. U.S.A. 106, 4054-4059. doi: 10.1073/pnas.0810086106

Stuss, D. T. (2006). Frontal lobes and attention: processes and networks, fractionation and integration. J. Int. Neuropsychol. Soc. 12, 261-271. doi: $10.1017 /$ S1355617706060358 
Treisman, A. M. (1969). Strategies and models of selective attention. Psychol. Rev. 76, 282-299. doi: 10.1037/h0027242

Conflict of Interest Statement: The author declares that the research was conducted in the absence of any commercial or financial relationships that could be construed as a potential conflict of interest.
Copyright $\odot 2015$ Coubard. This is an open-access article distributed under the terms of the Creative Commons Attribution License (CC BY). The use, distribution or reproduction in other forums is permitted, provided the original author(s) or licensor are credited and that the original publication in this journal is cited, in accordance with accepted academic practice. No use, distribution or reproduction is permitted which does not comply with these terms. 